\title{
Key Element Performance In Occupational Safety And Health Management System In Organization (A Literature)
}

\author{
Nuzaihan Aras Agus Salim ${ }^{1, a}$, Naziah Muhamad Salleh ${ }^{1}$ and Zuraihana Ahmad Zawawi ${ }^{2}$ \\ ${ }^{1}$ School of Housing, Building and Planning, Universiti Sains Malaysia, 11800 Penang, Malaysia \\ ${ }^{2}$ Faculty of Architecture, Planning and Surveying, Universiti Teknologi MARA Perak, 32610 Seri Iskandar, Perak, Malaysia
}

\begin{abstract}
Setting an effective safety and health management system is crucial in order to reduce problem relating to accident and ill in management organizational. It is involve with multiple level of management and stakeholders who empower the organization to the management in handling the safety and health cases and issues in organizational. It is necessary to prepare a well knowledge about safety and health management systems and preparing the framework for setting a certain scale in measuring its performance in this area. The successful or failure of management does showing the capability of the organization in delivering the responsible to management levels [1]. The problem in safe work issues and practices cause by the management commitment and involvement that create improper safety program and procedures, and this crisis keep continuing till present [2]. This paper describes about key element of safety and health management system and measuring the performance in order to get an effective management system in organization that describes the process in achieving effectiveness in management. The literature review will be conducted through the data collection from research findings and defined the strong character of key element in which focusing on measuring performance. A guide on key element performance in occupational safety and health management system is specifically drawn to prepare for a future research.
\end{abstract}

\section{Introduction}

Safety and health principles are universal, but how much action is needed will depend on the size of the organization, the hazards presented by its activities, the physical characteristics of the organization, products or services, and the adequacy of its existing arrangements. [3] stated that there were small mistakes can have a major effect and disaster do not have borders or nationalities, which is why nation should unite and promote occupational health and safety vigorously to reach the common goal of quick warning, prevention and protection systems for all. [4] rightfully mention that occupational health and safety is a complex international problem for management and society, and that it must always be a top priority.

[5] supports the view that the process of managing occupational health and safety are no different from that of other management activities, but is just that much more difficult because of its complexity. [6] said directors and senior managers must decide what is to be achieved by the organization and set in motion the necessary mechanism to achieve it. They must monitor progress and make changes when the desired objectives are not being achieved.

\section{Key Elements of a Safety and Health Management System}

The safety and health management is a common issue regarding the organization and workplace. [7], [8], [9], [10] described that the obligation of the managerial department in presenting on safety workplace and management in an organisation. However, a specific role model should be developing to in monitoring the organisation in safety and health management.

Accident, disasters and hazardous in workplace contribute to minor injury or even death to the workers. The organisation and management is always responsible and liable in the event of an accident at work. However, McDonald et.al. mentioned that there is not clear of any factor in neither a generally accepted model of the organisational in safety aspects, nor research on particular organisational forms and character of accident occurrence or accident description [11]. A blank space between between organisational forms and cases of accident occurrence could be established in a systematic monitoring and control. Organisation has a strong complex dynamic entity to ensure the application in functioning of safety.

\footnotetext{
${ }^{1}$ Corresponding author: nuzaihanaras@usm.my
} 
Safety Management becomes more important till today. It is a heart of the organisation to protect and secure their workers for harmful. The production of the core business is relying on this precious engine to run the business well. Historically, Hale et al., described that the development of safety management is establish since 1970's with followed reasons [12]:

I. Regulatory interest was stimulated by the changing philosophy which led to the framework legislation of the 1970s and 1980s in many European countries and ultimately to the consolidating European Framework Directive of 1989. Such legislation moved the emphasis from detailed technical safety concerns to issues of decision making and management formulated within a safety policy.

II. This trend was strengthened by a series of official reports following major disasters. The main emphasis in these reports was on the failings of management to ensure that their plant or activities were designed, operated and maintained with sufficient safety. Recent amendments to the post-Seveso Directive in 1994 require major hazard companies to have auditable safety management systems (SMS) and another directive have set up a voluntary European system for environmental management auditing.

III. In parallel with regulatory concerns with assessing safety management systems has been the increasing desire of governments to withdraw from their detailed regulatory tasks. The International Standards Organization standards on quality management systems have been, or are being used as a basis for devising standards for SMSs or related environmental management systems. The third party certification system which has grown up to assess compliance with the standards is increasingly seen, certainly in the Netherlands, as an opportunity for privatising some government assessment tasks.

The Figure 1 shows that the successful occupational safety and health management application in an organization on safety and health (Adapted from the Health and Safety Executive, 1997. Successful health and safety management. London: HSE Books)
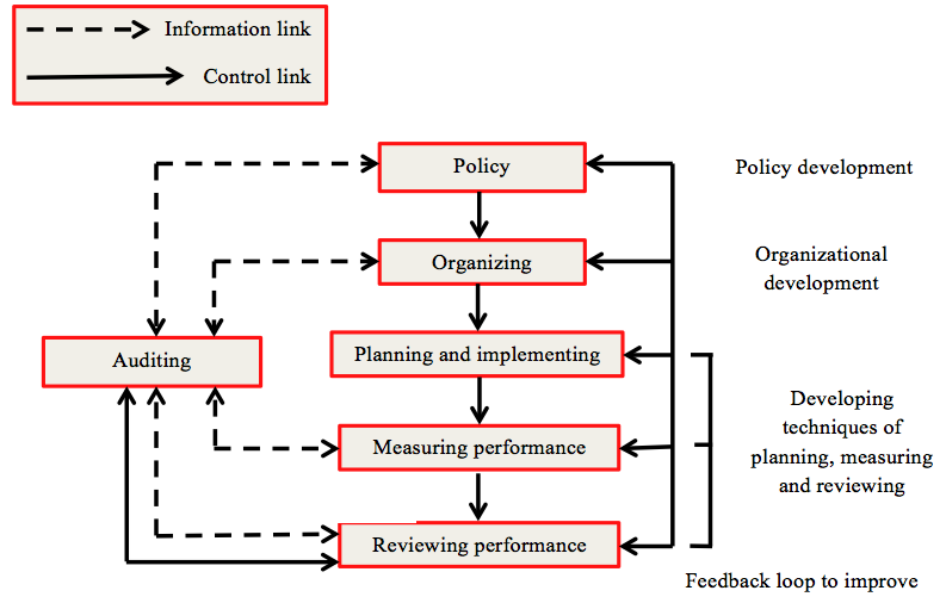

performance

Figure 1: Adapted from the Health and Safety Executive, 1997. Successful health and safety management. London: HSE Books

\section{Policy and Commitment}

According Health and Safety Executive, 1997, the organization should prepare an occupational safety and health policy programme as part of the preparation of the Safety Statement required by section 20 of the 2005 Act [13]. Effective safety and health policies should set a clear direction for the organization to follow. They will contribute to all aspects of business performance as part of a demonstrable commitment to continuous improvement. Responsibilities to people and the working environment will be met in a way that fulfills the spirit and letter of the law. Cost-effective approaches to preserving and developing human and physical resources will reduce financial losses and liabilities. In a wider context, stakeholders' expectations, whether they are shareholders, employees or their representatives, customers or society at large, can be met.

A research on Management of Occupational Health and Safety in Romania supports that every Organization essentially prepared and documented a health and safety policy to communicate their commitment to health and safety, and their arrangements and responsibilities for implementation. This must be consistent with health and safety policy [14].

i. The policy must include:

- Clear statement of overall health and safety objectives, with reference to Zero Harm

-commitment to the prevention of work related injuries and illnesses

-a commitment to continual improvement

-a commitment to compliance with all applicable legislation, PB Standards and accepted industry standards

ii. The policy must be approved and signed by the head of the organization.

iii. The policy must be communicated across the organization. 
The policy must be reviewed annually and revised where necessary to ensure that it remains relevant and appropriate to the organization.

\section{Organizing}

Jeffrey et.al. defined organizing as the process of creating a structure for the organization that will enable its human resources to work together effectively towards its objectives [15]. Organization hence refers to the result of the organizing process. According Health and Safety Executive, 1997 stated that the organization should formulate a plan to fulfill its safety and health policy as set out in the Safety Statement [13]. An effective management structure and arrangements should be put in place for delivering the policy. Safety and health objectives and targets should be set for all managers and employees.

\section{Implementation and operation}

For effective implementation, the organization should develop the capabilities and support mechanisms necessary to achieve its safety and health policy, objectives and targets. All staff should be motivated and empowered to work safely and to protect their long-term health, not simply to avoid accidents. The arrangements should be

- Underpinned by effective staff involvement and participation through appropriate consultation, the use of the safety committee where it exists, and representation systems.

- Sustained by effective communication and the promotion of competence which allows all employees and their representatives to make a responsible and informed contribution to the safety and health effort. There should be a planned and systematic approach to implementing the safety and health policy through an effective safety and health management system. The aim should be to minimize risks. Risk assessment methods should be used to determine priorities and set objectives for eliminating hazards and reducing risks. Wherever possible, risks should be eliminated through the selection and design of facilities, equipment and processes. If risks cannot be eliminated, they should be minimized by the use of physical controls and safe systems of work or, as a last resort, through the provision of personal protective equipment (PPE). Performance standards should be established and used for measuring achievement. Specific actions to promote a positive safety and health culture should be identified. There should be a shared common understanding of the organization's vision, values and beliefs. The visible and active leadership of senior managers fosters a positive safety and health culture.

\section{Workplace safety and health management}

Priorities and set objectives for eliminating hazards and reducing risks. Wherever possible, risks should be eliminated through the selection and design of facilities, equipment and processes. If risks cannot be eliminated, they should be minimized by the use of physical controls and safe systems of work or, as a last resort, through the provision of personal protective equipment. Performance standards should be established and used for measuring achievement. Specific actions to promote a positive safety and health culture should be identified. There should be a shared common understanding of the organization's vision, values and beliefs. The visible and active leadership of senior managers fosters a positive safety and health culture.

\section{Measuring Performance}

Ramroop mentioned that measurement is essential to maintaining and improving occupational health and safety performance. Organizations need to measure what they are doing to implement their occupational health and safety policy, to assess how effectively they are controlling risks, and how well they are developing a positive occupational health and safety culture [6].

Due to Health and Safety Executive, 1997, the organization should measure, monitor and evaluate its safety and health performance [13]. Performance can be measured against agreed standards to reveal when and where improvement is needed. Active self-monitoring reveals how effectively the health and safety management system is functioning. Self-monitoring looks at both hardware (premises, plant and substances) and software (people, procedures and systems, including individual behavior and performance). If controls fail, reactive monitoring should find out why they failed, by investigating the accidents, ill-health or incidents that could have caused harm or loss. The objectives of active and reactive monitoring are:

- To determine the immediate causes of substandard performance;

- To identify any underlying causes and implications for the design and operation of the safety and health management system. Longer-term objectives should also be monitored.

\section{Auditing and Reviewing Performance}

The Health and Safety Executive, 1997, stressed that the organization should review and improve its safety and health management system continuously, so that it is overall safety and health performance improves constantly [13]. The organization can learn from relevant experience and apply the lessons. There should be a systematic review of performance based on data from monitoring and from independent audits of the whole safety and health management system. These form the basis of complying with the organization's responsibilities under the 2005 Act and other statutory provisions. There should be a strong commitment to continuous improvement involving the development of policies, systems and techniques of risk control. Performance should be assessed by: 
- Internal reference to key performance indicators;

- External comparison with the performance of business competitors and best practice in the organization's employment sector. Many companies now report on how well they have performed on worker safety and health in their annual reports and how they have fulfilled their responsibilities with regard to preparing and implementing their safety statements. In addition, employers have greater responsibilities under section 80 of the 2005 Act on 'Liability of Directors and officers of undertakings' which requires them to be in a position to prove they have proactively managed the safety and health of their workers. Data from this 'Auditing and Reviewing Performance' process should be used for these purposes.

\section{Discussions}

In this article show that implementing effective occupational safety and health management system must follow a suitable guidelines to maximize the accident and ill health in organizational. The guidelines or policies must set as clear direction to getting effective in term of safety and health. Lastly, the study concluded that the use of key elements of a safety and health management system would contribute to successful occupational health and safety in an organization.

\section{References}

[1] Archie B.C. and Ann K.B., (2014), Business and Society: Ethics, Sustainability, and Stakeholder Management $9^{\text {th }}$ Edition, Cengage Learning, United State of America, ISBN-13: 978-1285734293.

[2] Coombs W.T., (2015), Public relations' "Relationship Identity" in research: Enlightenment or Illusion, Public Relations Review; A Global Journal of Research and Comment, Volume41, Issue 5, Pg. 689-695.

[3] Ramroop S., McCarthy J.J. and Naidoo K., (2004). Successful Occupational Health and Safety: A Management Perspective. Proceedings of 8th World Congress on Environmental Health. Document Transformation Technologies, South Africa, pp 22-27.

[4] Steenkamp and Van Schoor, (2008), The Quest For Quality of Work Life; A TQM Approach, Juta Education, Lansdowne, ISBN 0702151914.

1. [5] Boyle D., Larson C., Parker D., and Luisa P.B., (2000), Medical, personal, and occupational outcomes for work-related amputations in Minnesota, American
Journal of Industrial Medicine, Vol. 37, Issue 5, Pg. 551557.

[6] Ramroop S., and McCarthy, J. J., and Naidoo, K. (2004) Successful Occupational Health And Safety: A Management Perspective. Environmental Health Department, Ethekwini Municipality.

[7] Heinrich HW, Peterson D \& Roos N (1980), Industrial Accident Prevention, $5^{\text {th }}$ Edition, Mcgraw Hill, New York.

[8] Frank E. Bird, Jr. and Robert G. Loftus. (1976), Loss Control Management,

http://trove.nla.gov.au/version/12792176

[9] Petersen D.,(1978), Techniques of Safety Management, McGraw-Hill, New York (1978) 2nd Ed.

[10] Loomes M., Ridley D.,Diana K., (1994), Cognitive and Organisational Aspects of Design, Technology and Assessment of Safety-Critical Systems, SpringerVerlag London Limited.

[11] N. McDonald *, S. Corrigan, C. Daly, S. Cromie (2000). Safety management systems and safety culture in aircraft maintenance organisations, Journal of occuppational Accident, Volume 34, Issues 1-3, Pages 1258.

[12] Hale A.R., Heming B.H.J.,and Kirwan B., (1997), Modelling of Safety Management Systems, Journal of Occupational Accidents, Volume 26, Issues 1-2, JuneJuly 1997, Pages 121-140.

[13] Health and safety executive HSE. (1997).Successful Health and Safety management. London: HSE Books.

[14] Marius M., The Management of Occupational Helath and Safety in Romania, https://core.ac.uk/download/files/153/6695246.pdf.

[15] Jeffrey S. H. and Edward R. F. (1999), Stakeholders, Social Responsibility, and Performance: Empirical Evidence and Theoretical Perspectives, Academy of Management Journa, Vol. 42, pg. 479-485.

[16] Jeffrey S. H. and Edward R. F. (1999), Stakeholders, Social Responsibility, and Performance: Empirical Evidence and Theoretical Perspectives, Academy of Management Journa, Vol. 42, pg. 479-485. 